\title{
Article
}

\section{Optimal Installation Location of Escape Route Signs at T-Type Intersections}

\author{
Young-Hoon Bae ${ }^{1}{ }^{\mathbb{D}}$, Jong-Yeong Son ${ }^{2} \mathbb{D}$, Ryun-Seok Oh $^{3}$, Hye-Kyoung Lee ${ }^{1} \mathbb{D}$, Yoon-Ha Lee ${ }^{4}$, Won-Hwa Hong ${ }^{1}$ \\ and Jun-Ho Choi ${ }^{3,5, *(D)}$
}

1 School of Architectural, Civil, Environmental and Energy Engineering, Kyungpook National University, Daegu 41566, Korea; byh0105@gmail.com (Y.-H.B.); trot36@hanmail.net (H.-K.L.); hongwonhwa@gmail.com (W.-H.H.)

2 Disaster Information Research Division, National Disaster Management Research Institute, Ulsan 44538, Korea; ssonjy2239@gmail.com

3 Research Institute of Intelligent Fire Safety Technology and Human Behavioural Science, Pukyong National University, Busan 48513, Korea; kaing367@gmail.com

4 Department of Fire and Disaster Prevention Engineering, Changshin University, Changwon 51352, Korea; dldbsgk123@naver.com

5 Division of Architectural and Fire Protection Engineering, Pukyong National University, Busan 48513, Korea

* Correspondence: jchoi@pknu.ac.kr; Tel.: +82-(0)51-629-7830

check for updates

Citation: Bae, Y.-H.; Son, J.-Y.; Oh, R.-S.; Lee, H.-K.; Lee, Y.-H.; Hong, W.-H.; Choi, J.-H. Optimal Installation Location of Escape Route Signs at T-Type Intersections. Sustainability 2021, 13, 7903. https://doi.org/ $10.3390 /$ su13147903

Academic Editor: Francesco Faccini

Received: 9 June 2021

Accepted: 11 July 2021

Published: 15 July 2021

Publisher's Note: MDPI stays neutral with regard to jurisdictional claims in published maps and institutional affiliations.

Copyright: (c) 2021 by the authors. Licensee MDPI, Basel, Switzerland. This article is an open access article distributed under the terms and conditions of the Creative Commons Attribution (CC BY) license (https:/ / creativecommons.org/licenses/by/ $4.0 /)$.

\begin{abstract}
This study analyzed the decision-making times (DMTs) of participants at T-type indoor intersections according to the horizontal/vertical installation locations and the arrow directions of escape route signs. A total of 120 university students participated in the study. We analyzed the DMTs and following rates (FRs) required for the participants to observe the visual stimuli of the signs installed in front of the T-type indoor intersections and then properly select a path according to the arrow direction of the signs. The results are as follows: (1) the participants exhibited shorter DMTs for the right arrow direction of the signs, (2) the Simon effect occurred when the horizontal installation location of the signs was more than $60 \mathrm{~cm}$ away from the center of the T-type indoor intersection on both sides, (3) the DMTs of participants increased when the vertical installation location of the signs was low. Finally, we proposed an optimal installation location of the signs to support the shortest DMTs at T-type indoor intersections. It is expected that the results of this study will provide a database of DMTs, based on the locations of the signs during emergency evacuations, and will be utilized to improve the installation guidelines and regulations of signs.
\end{abstract}

Keywords: escape route signs; decision-making times; virtual stimuli; T-type intersection; optimal installation location

\section{Introduction}

Since the evacuation time is a decisive survival factor during disasters, such as fires, severe weather events, or terrorist attacks [1,2], accurate ways of finding escape routes and quick decision making are extremely important during evacuations [3]. Escape route signs are installed in buildings to support the occupants' decision making during evacuations. Given the important role of signs in the evacuation process, which includes wayfinding and decision making, design guidelines and regulations affect the performance of signs, including their sizes, colors, and fonts, as well as sign locations, additional lighting, and construction materials [4-6]. However, numerous studies have verified that the signs installed according to established guidelines and regulations cannot effectively support decision making $[7,8]$.

To overcome this limitation, various studies have been conducted regarding the development of efficient signs and the designation of their optimal installation locations. Prior studies have attempted to increase the affordance of signs, considering variables such as size [9,10], brightness [11], colors and graphics [12-15], lighting method [16-20], 
and smoke [21,22]. These studies have been successful in improving signs' affordances, by altering the performance of signs, but no analysis has been conducted on the interaction between signs and humans that considers the installation location or arrow directions.

Previous studies aimed at determining the optimal installation locations of signs assumed that evacuees could recognize signs when they were in "the light coverage area of the closest sign", and presented only the installation locations of signs, where the coverage areas included the locations of all buildings [23,24]. The recognition of signs by evacuees was determined by the distance and angle between them and the signs, whereas the interaction between signs and humans, according to the horizontal/vertical installation locations and arrow directions was not considered.

Recently, several studies have been conducted to derive the installation location of signs, considering the interaction between signs and humans. These studies, however, neither sufficiently considered the horizontal/vertical installation locations, nor the arrow directions of the signs. Zhang et al. [25] proposed a model for deriving the optimal installation locations of signs, which determines the "viewing distance" of the sign and derives an optimal installation location based on the concept of "the attractiveness of a sign". The attractiveness of a sign affects people based on the size and color of signs by reflecting the interaction between humans and signs. However, they did not explain the interaction between signs and humans according to the horizontal/vertical installation locations or arrow directions. Bae et al. [26] conducted research to propose the installation locations of signs based on the analysis of the gaze points of evacuees at various intersections. The study, however, had limitations because experiments were performed at intersections with no installed signs, and the installation locations were determined based on the assumption that the efficiency of signs would increase if installed in locations that attract the attention of more people. In addition, Kim et al. [27] analyzed the decision-making time of evacuees according to the installation locations of signs and verified the Stroop facilitation and interference effects. However, they analyzed the interaction between signs and humans only at three (left, center, and right) horizontal installation locations and did not consider the installation height.

To the best of our knowledge, no prior study has analyzed the interaction between evacuees and signs by considering both the horizontal/vertical installation locations and the arrow directions of signs. To overcome this limitation, this study analyzed the decision-making time of participants in T-type indoor intersections according to the horizontal/vertical installation locations and the arrow directions of signs (signs in this study represents those composed of arrow symbols). The aim is to provide the optimal installation location of signs based on the results of our analysis. To this end, a total of 198 virtual stimuli, including images containing signs installed in front of virtual T-type indoor intersections, were prepared. The 198 images were obtained through a combination of 99 installation locations with left and right arrow directions. An experiment was then performed requiring participants to observe the virtual stimuli and select either the left or right path according to the arrow direction of the signs. Through the analysis of the experimental results, decision-making times (DMTs) and following rates (FRs) were derived according to the arrow direction and the installation location of the signs. Following rates indicate the number of trials when the response was identical to the direction of the signs divided by the number of total trials [27]. In addition, variances in DMTs depending on the arrow direction and installation location of signs were analyzed statistically. Finally, the optimal installation location of the signs that supports the shortest DMTs at T-type indoor intersections was proposed based on the experimental results. It is expected that the results of this study will provide a database of DMTs based on the locations of the signs during emergency evacuations and will be utilized to improve the installation guidelines and regulations of signs. 


\section{Material and Methods}

\subsection{Participants}

We placed recruitment advertisements on online bulletin boards to recruit the participants. The participants included 120 university students (76 men and 44 women), ranging between 20 and 36 years of age (mean $[\mathrm{M}]=23.21$, standard deviation $[\mathrm{SD}]=2.07$ ) exhibiting normal or corrected to normal vision. Veeraswamy et al. [28] discovered a significant variance between right-handed and left-handed people in their choice of routes. Therefore, as the experiment involved looking at the virtual stimuli and choosing a route, all selected subjects were right-handed.

\subsection{Experimental Environment}

The purpose of this study was to analyze the decision-making time of the participants, according to the installation location and arrow directions of signs. An experiment was performed to analyze the DMTs and FRs that required to the participants to observe the visual stimuli of the signs installed in front of the T-type indoor intersections and then properly select a path according to the arrow direction of the signs. In the experiment, each participant observed the visual stimuli presented on a 24-inch light-emitting diode (LED) monitor screen, and then selected the arrow direction of the signs on a keyboard.

Visual stimuli consisted of two variables, which included the installation location, and the arrow direction of the signs. The installation location of the signs was divided into vertical and horizontal installation locations of the signs. The vertical installation location of signs included nine cases at $30 \mathrm{~cm}$ intervals $(y=30 \mathrm{~cm}, y=60 \mathrm{~cm}, y=90 \mathrm{~cm}, y=120 \mathrm{~cm}$, $\mathrm{y}=150 \mathrm{~cm}, \mathrm{y}=180 \mathrm{~cm}, \mathrm{y}=210 \mathrm{~cm}, \mathrm{y}=240 \mathrm{~cm}$, and $\mathrm{y}=270 \mathrm{~cm})$, whereas the horizontal installation location included 11 cases, also at $30 \mathrm{~cm}$ intervals $(x=-150 \mathrm{~cm}, x=-120 \mathrm{~cm}$, $x=-90 \mathrm{~cm}, x=-60 \mathrm{~cm}, x=-30 \mathrm{~cm}, x=0 \mathrm{~cm}, x=30 \mathrm{~cm}, x=60 \mathrm{~cm}, x=90 \mathrm{~cm}, x=120 \mathrm{~cm}$, and $x=150 \mathrm{~cm}$ ). The arrow direction of the signs included two cases, which were the "left arrow" and the "right arrow". Finally, the 198 visual stimuli obtained through the combination of the installation locations and arrow directions of the signs were used in the experiment (see Figure 1).

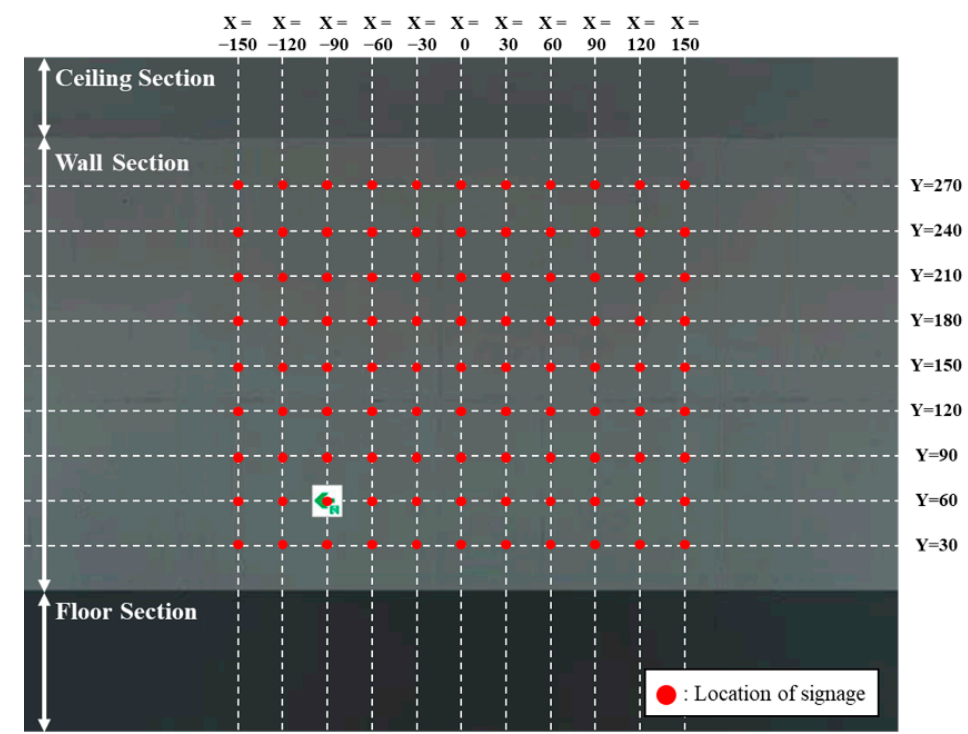

(a)

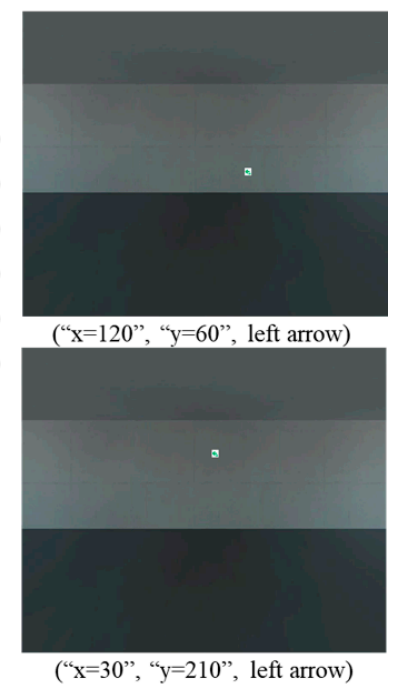

(b)

Figure 1. Examples of the visual stimuli: (a) the installation location of signs (The visual stimuli consist of the ceiling section, wall section, and floor section. The red points in the wall section represent 99 installation locations of signs in each virtual stimulus); (b) examples of the visual stimuli used in the experiment. 
Variables other than the installation locations and arrow directions of the sign were the same for all visual stimuli. The color and shape of the signs used for the visual stimuli were the same as the standards of the Graphical Symbols-Safety colors (ISO 3864-3) and National Fire Safety Code (NFSC) 303: Fire Safety Regulation of Exit Light and Exit Sign [4,29], with a size of $200 \mathrm{~mm} \times 200 \mathrm{~mm}$, which is the size of the signs typically sold in South Korea. The space of the visual stimuli was produced using Autodesk's Revit software, assuming the participant was located $10 \mathrm{~m}$ in front of the T-type indoor intersection of a building with a floor height of $3 \mathrm{~m}$. The wall of the visual stimuli was produced by assuming a concrete wall, and neither the luminance of the signs or the illumination of the space were considered.

Each participant was seated in a chair and observed the 24-inch LED monitor screen on a desk in front of them. The distance between the chair and the monitor was adjusted to emulate the environment in which the participants would observe the signs of a T-type indoor intersection $10 \mathrm{~m}$ ahead during an evacuation. To maintain the distance between the participant and the monitor during the experiment, the participants were asked to sit with a straight back and good posture (see Figure 2).

Wall height of virtual stimuli $(3000 \mathrm{~mm})$ : Distance to wall of virtual stimuli $(10,000 \mathrm{~mm})$ $=$ Wall height in monitor $(110 \mathrm{~mm}):$ Distance to wall in monitor $(x \mathrm{~mm})$

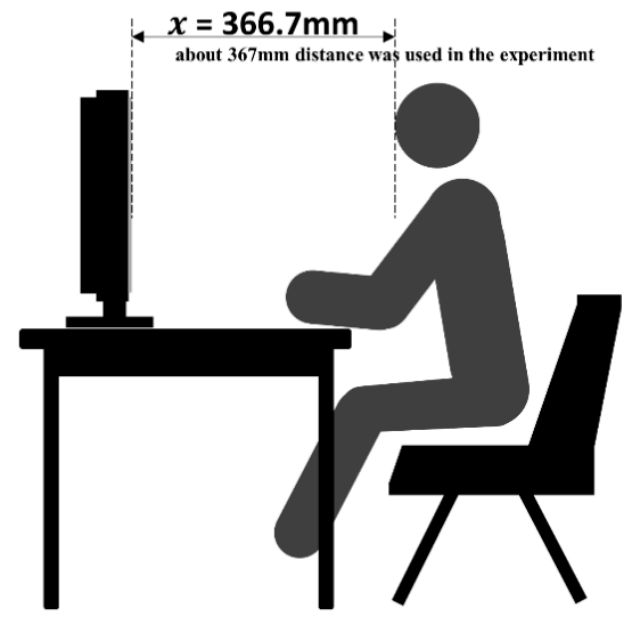

(a)

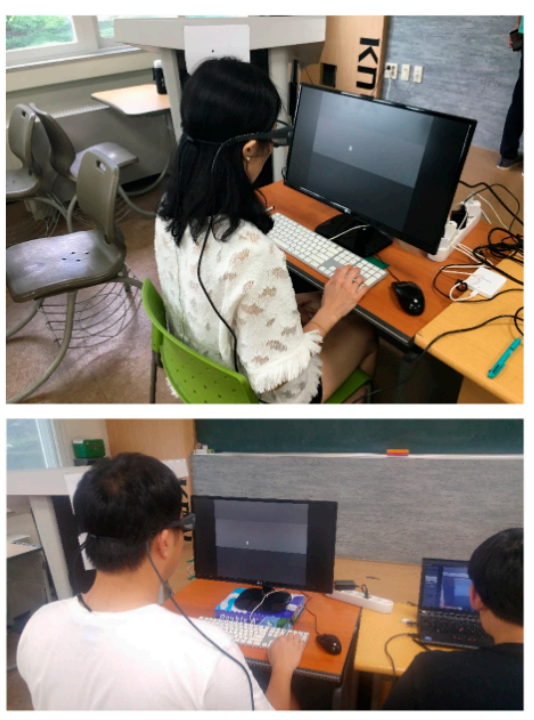

(b)

Figure 2. Configuration of the experimental environment and the scenes of the experiment: (a) designation of the distance between the monitor and the participant (the distance is selected using a proportional expression); (b) experiment snapshot.

The experiment scenario was produced using Cedrus's Superlab 5.0 software, and all the participants participated in the experiment after one preliminary experiment. The 198 visual stimuli appeared randomly, and each stimulus was presented at $1000 \mathrm{~ms}$ intervals after the response to the previous stimulus (see Figure 3). 


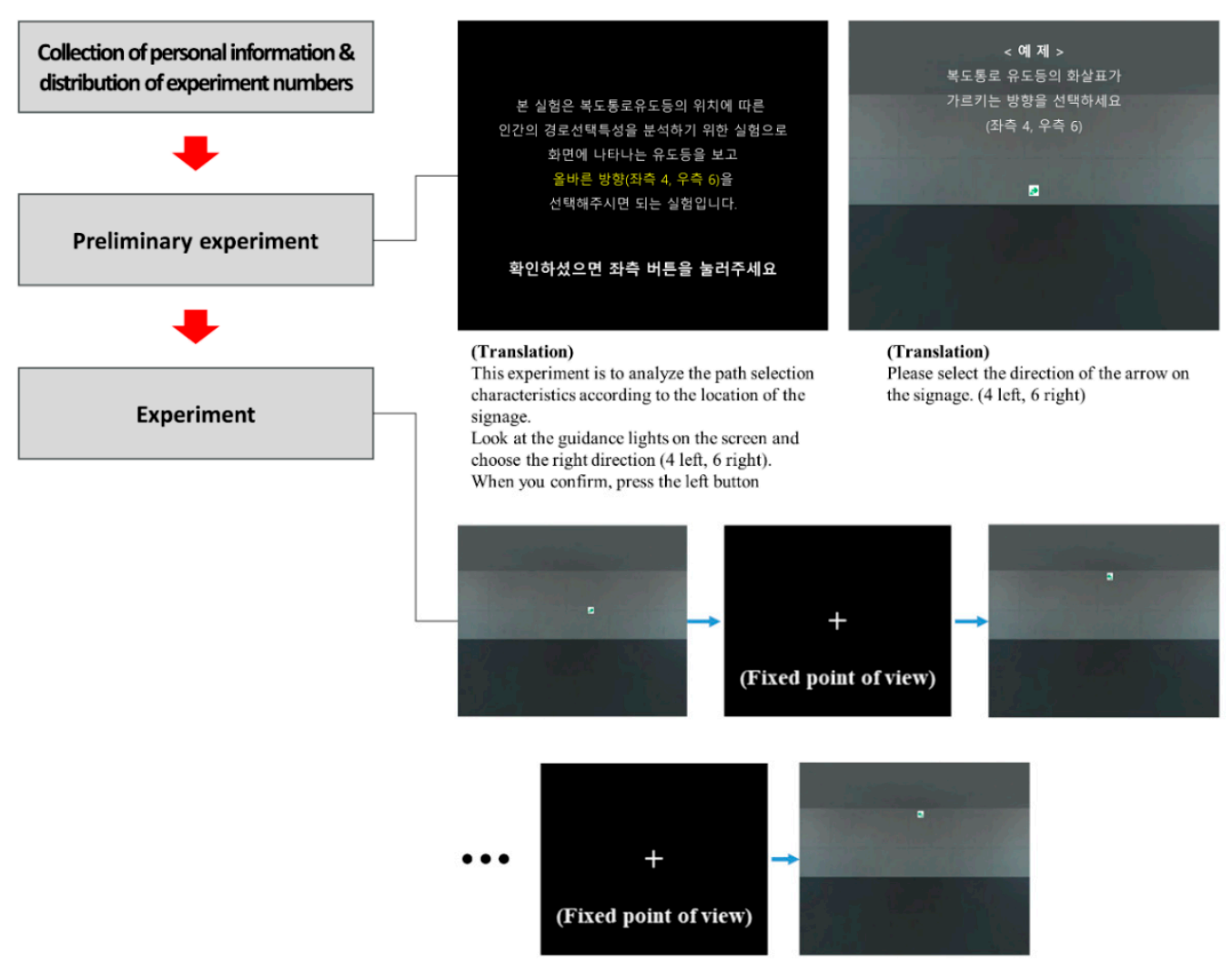

Figure 3. Experimental procedure (the experiment was performed in order of "collection of personal information and distribution of experiment numbers", "preliminary experiment", and "experiment").

\subsection{Experimental Procedure}

Figure 3 shows the experimental procedure. Before beginning the experiment, the participants were assigned identification numbers, and their personal information was documented (e.g., gender and age). The participants participated in the experiment after the method was explained to them by the experimental staff. They were directed to select the evacuation direction (right or left) according to the arrow direction of the signs in the virtual stimuli as if they were at a T-type intersection in an evacuation situation. The participants were instructed to press the "number 4 key (left arrow)" on the number pad of the keyboard when the signs ahead indicated the left arrow direction, and "number 6 key (right arrow)" when it revealed the right arrow direction. Participants were also instructed to respond to the virtual stimuli as quickly as possible and after each response, to concentrate on a fixed central point, until the next virtual stimulus was presented.

\subsection{Results Analysis Method}

The time required for participants to select a path (DMTs), and the participant selected directions were analyzed. First, the average DMT and FRs according to the arrow direction of signs were calculated, and DMT variances ascribed to arrow directions were statistically tested using the $t$-test. The average DMT was calculated according to the DMTs by which the participants selected the correct direction. DMTs by which the wrong direction was selected were excluded from the average value. Second, DMTs and FRs according to the horizontal installation location and arrow direction of signs were compared and analyzed. Variances in DMTs depending on the horizontal installation location of the signs were statistically tested through an analysis of variance (ANOVA), and the significant variances in DMTs depending on the arrow direction at each horizontal installation location were statistically tested through a $t$-test. Third, the DMTs and FRs were compared and analyzed according to the vertical installation location and arrow direction of signs. As in the previous statistical test method, variances in DMTs depending on the vertical installation 
location of the signs and significant variances in DMTs depending on the arrow direction at each vertical installation location were tested through ANOVA and $t$-test. These data analyses were conducted using SPSS 21.

\section{Results}

The average DMTs for each sign's installation location based on the experimental results are shown in Figures 4-6. Figure 4 shows the average DMTs of the entire experiment; Figures 5 and 6 show the average DMTs for the left arrow direction of the signs and the average DMTs for the right arrow direction, respectively. They intuitively present the magnitudes of the average DMTs for each installation location according to the grading of the average DMTs. Five ranks were divided into equal intervals, based on the maximum (1946.73 ms) and minimum (1472.50 ms) values of the average DMTs, according to the installation locations and arrow directions of the signs.

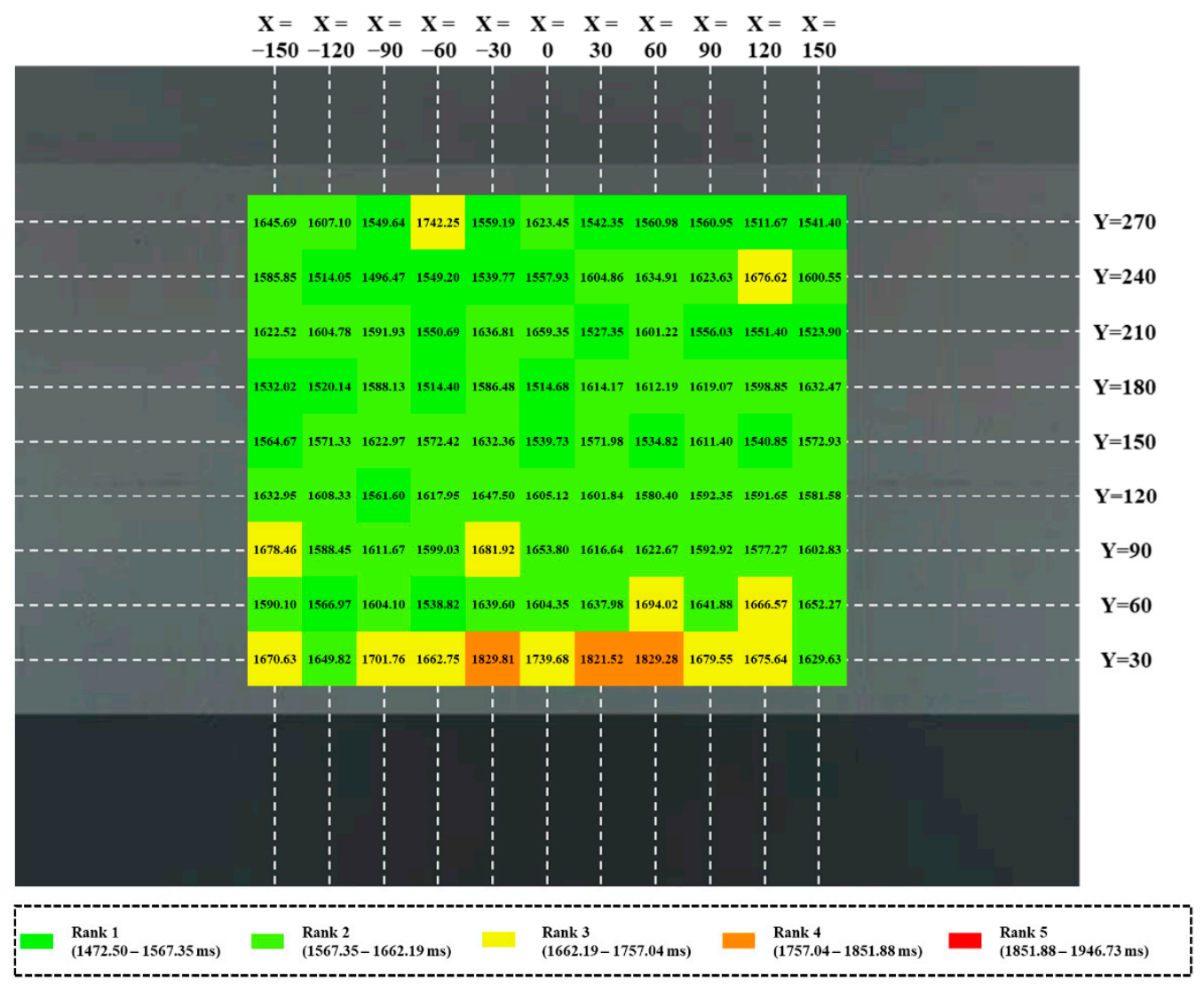

Figure 4. Average DMTs and grading results for each signs installation location for all arrow directions of signs. 


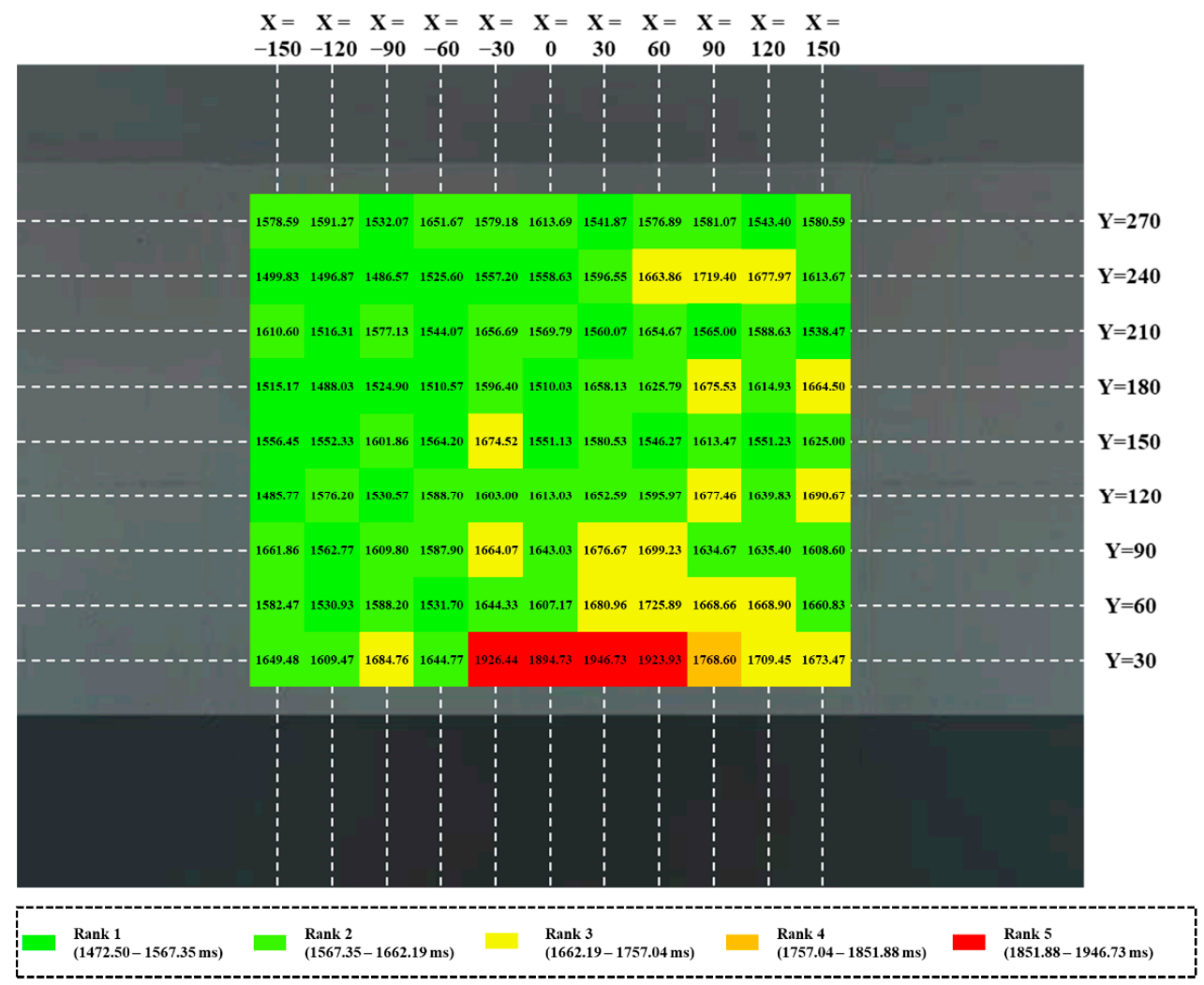

Figure 5. Average DMTs and grading results for each signs installation location for the left arrow direction of signs.

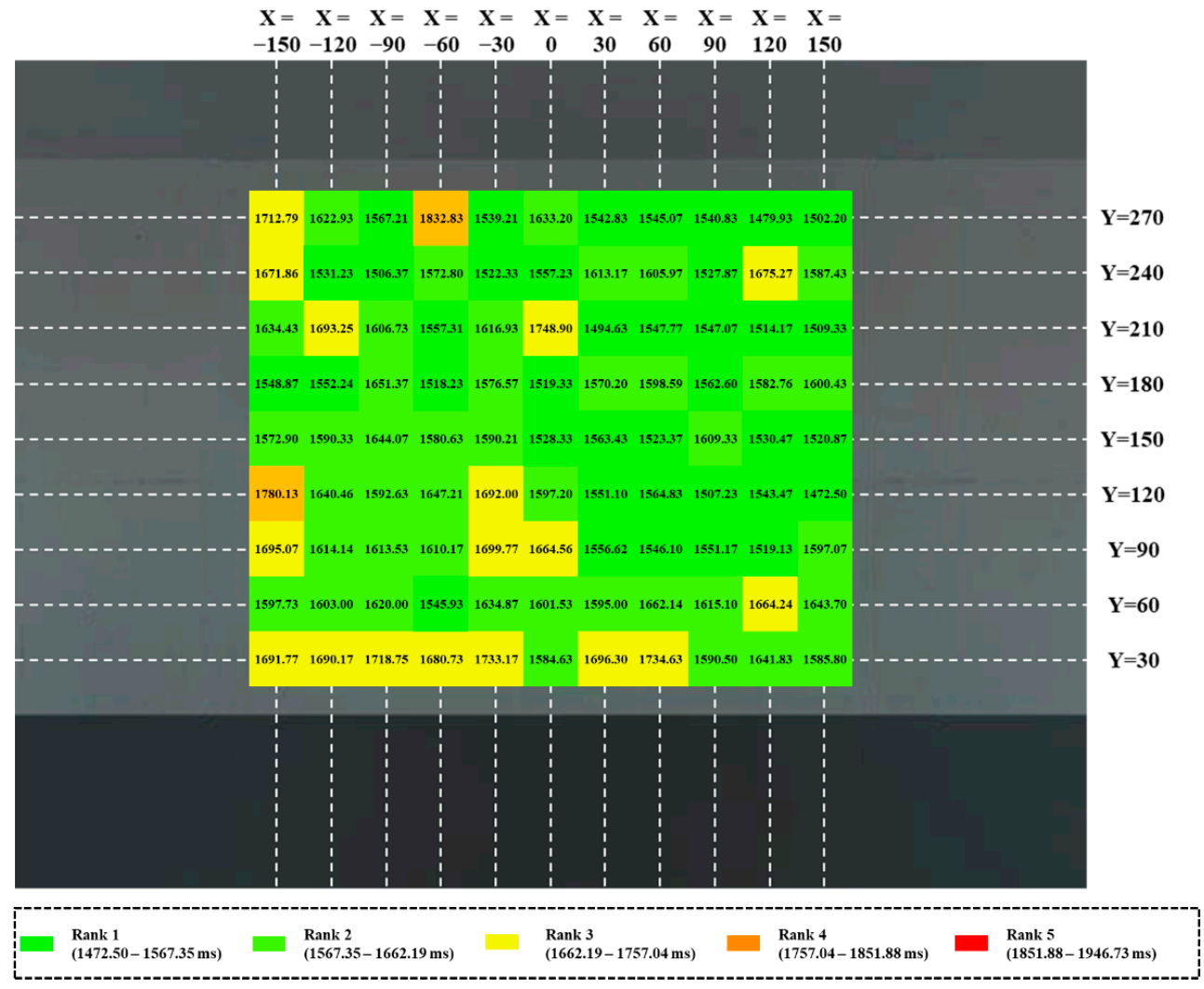

Figure 6. Average DMTs and grading results for each signs installation location for the right arrow direction of signs. 
To analyze the significant variances depending on the installation locations and arrow directions of the signs, the average DMTs and FRs according to the arrow directions of the signs were analyzed first (see Table 1). The average DMTs for both left and right arrow directions was found to be $1606.55 \mathrm{~ms}$ ( $\mathrm{SD}=227.10 \mathrm{~ms}$ ) and FRs was $98.82 \%$. As for the arrow direction of signs, the left arrow direction of the signs exhibited a longer average DMT and lower FRs (average DMT $=1614.98 \mathrm{~ms}$, SD $=211.88 \mathrm{~ms}$, FRs $=98.76 \%$ ) than the right arrow direction (average DMT $=1598.12 \mathrm{~ms}, \mathrm{SD}=241.08 \mathrm{~ms}, \mathrm{FRs}=98.88 \%$ ). The $t$-test results revealed that the DMTs differed, depending on the direction of signs $(p=0.000<0.05)$. The participants exhibited shorter DMTs and higher FRs when they recognized the right arrow of the signs and selected the right direction.

Table 1. Average DMTs and FRs according to the arrow direction (SD, standard deviation; Sig. Statistical significance).

\begin{tabular}{cccccc}
\hline Arrow Direction & Average DMTs (ms) & SD (ms) & FRs (\%) & t & Sig. \\
\hline Total & 1606.55 & 227.10 & 98.82 & & \\
Left & 1614.98 & 211.88 & 98.76 & & \\
Right & 1598.12 & 241.08 & 98.88 & 5.691 & 0.000 \\
\hline
\end{tabular}

Table 2 shows the average DMTs and FRs according to the horizontal installation location of the signs. The lowest average DMT (1581.35 ms) was observed when the horizontal installation location was $x=-120 \mathrm{~cm}$, and the ANOVA results revealed that there were significant variances in DMTs, depending on the horizontal installation location $(p=0.000<0.05)$. Figure 7 and Table 3 show the results of DMTs and FRs, according to the horizontal installation location and arrow direction of the signs. For the left arrow direction, the horizontal installation location with the lowest average DMT (1547.22 ms) was found to be $\mathrm{x}=-120 \mathrm{xm}$, which was located to the left of the center. For the right arrow direction, the lowest average DMT (1557.81 ms) was observed at $x=150 \mathrm{xm}$ which was located to the right of the center. A $t$-test was conducted at each horizontal installation location to analyze the variances depending on the arrow direction at each location. It was found that there were significant variances in DMTs, depending on the arrow direction at all horizontal installation locations, except for $\mathrm{x}=0 \mathrm{~cm}(p=0.142>0.05)$, which was the central location of the signs in the horizontal direction. At $x=-150 \mathrm{~cm}, x=-120 \mathrm{~cm}, x=-90 \mathrm{~cm}$, and $\mathrm{x}=-60 \mathrm{~cm}$ which were located to the left of the center, the average DMTs were found to be shorter and FRs was higher for the left arrow direction. At $x=60 \mathrm{~cm}, x=90 \mathrm{~cm}, x=120 \mathrm{~cm}$, and $x=150 \mathrm{~cm}$, which were located to the right of the center, the average DMTs were shorter and FRs was higher for the right arrow direction. At $x=-30 \mathrm{~cm}, x=0 \mathrm{~cm}$, and $\mathrm{x}=30 \mathrm{~cm}$, the average DMTs were shorter for the right arrow direction.

Table 2. Average DMTs and ANOVA results according to the horizontal installation location of signs (SD, standard deviation; Sig. Statistical significance).

\begin{tabular}{|c|c|c|c|c|c|}
\hline $\begin{array}{l}\text { Horizontal Installation } \\
\text { Location }(\mathrm{cm})\end{array}$ & Average DMTs (ms) & SD (ms) & FRs (\%) & $\mathbf{F}$ & Sig. \\
\hline$x=-150$ & 1604.48 & 214.03 & 97.31 & \multirow{7}{*}{3.222} & \multirow{7}{*}{0.000} \\
\hline$x=-120$ & 1581.35 & 184.92 & 98.80 & & \\
\hline$x=-90$ & 1593.65 & 222.78 & 98.84 & & \\
\hline$x=-60$ & 1597.18 & 331.09 & 99.07 & & \\
\hline$x=-30$ & 1642.08 & 215.46 & 98.94 & & \\
\hline$x=0$ & 1612.57 & 232.99 & 99.26 & & \\
\hline$x=30$ & 1616.61 & 225.96 & 99.31 & & \\
\hline
\end{tabular}


Table 2. Cont.

\begin{tabular}{|c|c|c|c|c|c|}
\hline $\begin{array}{l}\text { Horizontal Installation } \\
\text { Location }(\mathrm{cm})\end{array}$ & Average DMTs (ms) & $\mathrm{SD}(\mathrm{ms})$ & FRs (\%) & $\mathbf{F}$ & Sig. \\
\hline$x=60$ & 1630.56 & 201.94 & 99.17 & & \\
\hline$x=90$ & 1608.93 & 210.26 & 99.12 & & \\
\hline$x=120$ & 1599.28 & 219.97 & 98.33 & & \\
\hline$x=150$ & 1593.21 & 210.24 & 98.89 & & \\
\hline Total & 1607.21 & 227.75 & 98.82 & & \\
\hline
\end{tabular}

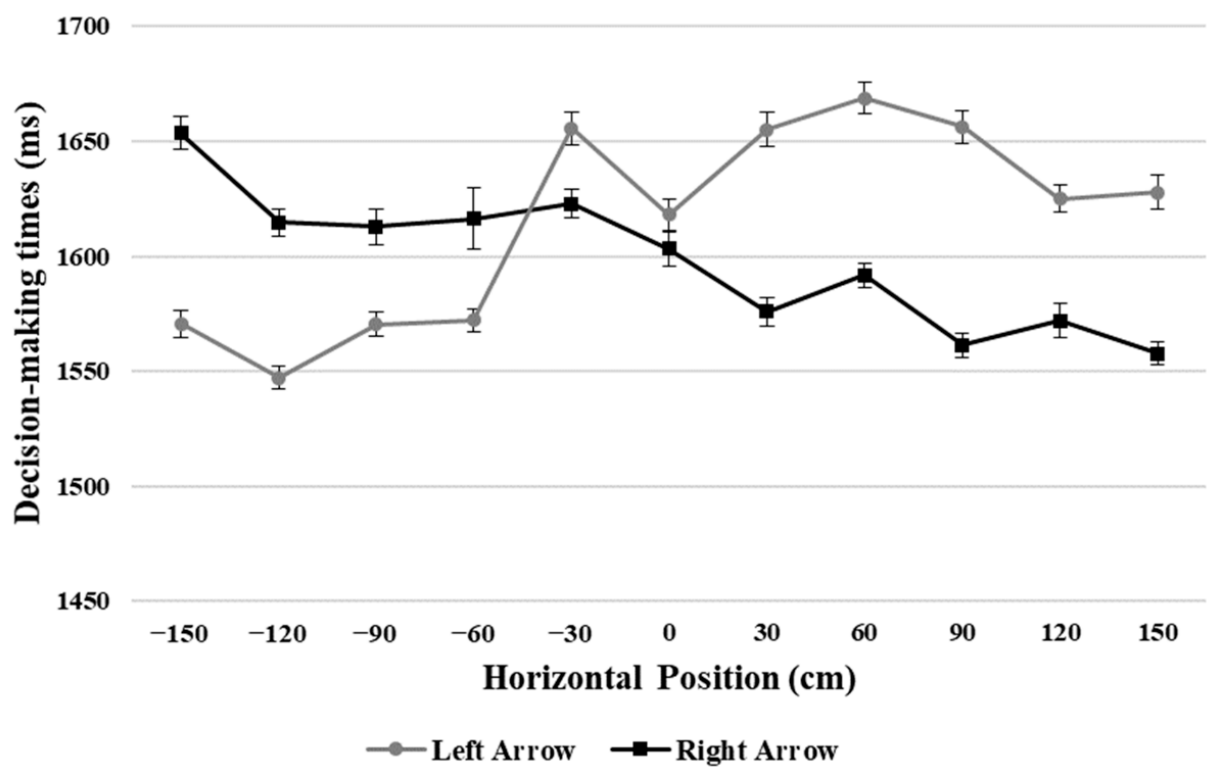

Figure 7. Average DMTs according to the horizontal installation location and arrow direction (the error bars represent standard errors).

Table 3. Average DMTs and FRs according to the horizontal installation location and arrow direction (L, left; R, right; SD, standard deviation; Sig. Statistical significance).

\begin{tabular}{|c|c|c|c|c|c|c|}
\hline $\begin{array}{l}\text { Horizontal Installation } \\
\text { Location }(\mathrm{cm})\end{array}$ & $\begin{array}{c}\text { Arrow } \\
\text { Direction }\end{array}$ & $\begin{array}{c}\text { Average } \\
\text { DMTs (ms) }\end{array}$ & $\begin{array}{l}\mathrm{SD} \\
(\mathrm{ms})\end{array}$ & $\begin{array}{l}\text { FRs } \\
(\%)\end{array}$ & $\mathbf{t}$ & Sig. \\
\hline \multirow{2}{*}{$x=-150$} & $\mathrm{~L}$ & 1570.54 & 197.33 & 98.70 & \multirow{2}{*}{-8.931} & \multirow{2}{*}{0.000} \\
\hline & $\mathrm{R}$ & 1653.50 & 227.02 & 95.93 & & \\
\hline \multirow{2}{*}{$x=-120$} & $\mathrm{~L}$ & 1547.22 & 161.17 & 99.72 & \multirow{2}{*}{-8.635} & \multirow{2}{*}{0.000} \\
\hline & $\mathrm{R}$ & 1614.66 & 197.48 & 97.87 & & \\
\hline \multirow{2}{*}{$x=-90$} & $\mathrm{~L}$ & 1570.39 & 176.60 & 99.07 & \multirow{2}{*}{-4.419} & \multirow{2}{*}{0.000} \\
\hline & $\mathrm{R}$ & 1612.77 & 258.71 & 98.61 & & \\
\hline \multirow{2}{*}{$x=-60$} & $\mathrm{~L}$ & 1572.18 & 169.00 & 99.26 & \multirow{2}{*}{-3.083} & \multirow{2}{*}{0.002} \\
\hline & $\mathrm{R}$ & 1616.33 & 436.62 & 98.89 & & \\
\hline \multirow{2}{*}{$x=-30$} & $\mathrm{~L}$ & 1655.63 & 229.04 & 98.61 & \multirow{2}{*}{3.54} & \multirow{2}{*}{0.000} \\
\hline & $\mathrm{R}$ & 1622.9 & 196.96 & 99.26 & & \\
\hline \multirow{2}{*}{$x=0$} & $\mathrm{~L}$ & 1618.01 & 222.59 & 99.35 & \multirow{2}{*}{1.468} & \multirow{2}{*}{0.142} \\
\hline & $\mathrm{R}$ & 1603.32 & 240.66 & 99.17 & & \\
\hline
\end{tabular}


Table 3. Cont.

\begin{tabular}{|c|c|c|c|c|c|c|}
\hline $\begin{array}{l}\text { Horizontal Installation } \\
\text { Location }(\mathrm{cm})\end{array}$ & $\begin{array}{c}\text { Arrow } \\
\text { Direction }\end{array}$ & $\begin{array}{c}\text { Average } \\
\text { DMTs (ms) }\end{array}$ & $\begin{array}{l}\text { SD } \\
(\mathrm{ms})\end{array}$ & $\begin{array}{l}\text { FRs } \\
(\%)\end{array}$ & $\mathbf{t}$ & Sig. \\
\hline \multirow{2}{*}{$x=30$} & $\mathrm{~L}$ & 1655.01 & 242.02 & 98.52 & \multirow{2}{*}{8.285} & \multirow{2}{*}{0.000} \\
\hline & $\mathrm{R}$ & 1575.85 & 197.06 & 99.26 & & \\
\hline \multirow{2}{*}{$x=60$} & $\mathrm{~L}$ & 1668.82 & 214.81 & 97.31 & \multirow{2}{*}{8.992} & \multirow{2}{*}{0.000} \\
\hline & $\mathrm{R}$ & 1591.77 & 177.99 & 99.35 & & \\
\hline \multirow{2}{*}{$x=90$} & $\mathrm{~L}$ & 1656.27 & 227.77 & 98.24 & \multirow{2}{*}{10.767} & \multirow{2}{*}{0.000} \\
\hline & $\mathrm{R}$ & 1561.30 & 176.66 & 100 & & \\
\hline \multirow{2}{*}{$x=120$} & $\mathrm{~L}$ & 1625.01 & 188.99 & 98.80 & \multirow{2}{*}{5.662} & \multirow{2}{*}{0.000} \\
\hline & $\mathrm{R}$ & 1571.99 & 240.99 & 99.54 & & \\
\hline \multirow{2}{*}{$x=150$} & $\mathrm{~L}$ & 1627.87 & 238.95 & 98.80 & \multirow{2}{*}{7.902} & \multirow{2}{*}{0.000} \\
\hline & $\mathrm{R}$ & 1557.81 & 164.49 & 99.81 & & \\
\hline
\end{tabular}

Next, the DMTs and FRs, according to the vertical installation location of the signs, were analyzed. As shown in Table 4, the lowest average DMT (1577.04 ms) was observed at $\mathrm{y}=150 \mathrm{~cm}$, whereas the highest average DMT $(1717.75 \mathrm{~ms})$ was observed at $\mathrm{y}=30 \mathrm{~cm}$. The ANOVA results revealed there were significant variances in DMTs depending on the vertical installation location $(p=0.000<0.05)$.

Table 4. Average DMTs and ANOVA results according to the vertical installation location of signs (SD, standard deviation; Sig. Statistical significance).

\begin{tabular}{|c|c|c|c|c|c|}
\hline $\begin{array}{l}\text { Vertical Installation } \\
\text { Location }(\mathrm{cm})\end{array}$ & Average DMTs (ms) & $\mathrm{SD}(\mathrm{ms})$ & FRs (\%) & $\mathbf{F}$ & Sig. \\
\hline$y=30$ & 1717.75 & 285.08 & 92.52 & \multirow{10}{*}{26.113} & \multirow{10}{*}{0.000} \\
\hline$y=60$ & 1620.70 & 181.44 & 98.79 & & \\
\hline$y=90$ & 1620.82 & 252.04 & 99.13 & & \\
\hline$y=120$ & 1599.19 & 211.53 & 97.80 & & \\
\hline$y=150$ & 1577.04 & 180.73 & 99.09 & & \\
\hline$y=180$ & 1577.65 & 206.46 & 99.43 & & \\
\hline$y=210$ & 1586.74 & 178.57 & 98.94 & & \\
\hline$y=240$ & 1582.78 & 183.42 & 99.32 & & \\
\hline$y=270$ & 1584.25 & 291.62 & 98.37 & & \\
\hline Total & 1607.21 & 227.75 & 98.82 & & \\
\hline
\end{tabular}

Table 5 and Figure 8 show the DMTs and FRs results according to the arrow direction and vertical installation location of the signs. The average DMTs for both, the left and right arrow directions were found to be the highest at $y=30 \mathrm{~cm}$. For the left arrow direction, the lowest average DMT was observed at $y=270 \mathrm{~cm}$ (average DMT $=1579.21 \mathrm{~ms}$ ). For the right arrow direction, the lowest average DMT was observed at $y=150 \mathrm{~cm}$ (average DMT $=1568.25 \mathrm{~ms}$ ). In addition, when the $t$-test was conducted to analyze significant variances in DMTs depending on the arrow direction, there was no significant variance in DMTs depending on the arrow direction of signs at all vertical installation locations except for $\mathrm{y}=30 \mathrm{~cm}$ and $\mathrm{y}=90 \mathrm{~cm}(\mathrm{y}=30, p=0.000<0.05 ; \mathrm{y}=90, p=0.003<0.05)$. 
Table 5. Average DMTs and FRs according to the vertical installation location and arrow direction (L, left; R, right; SD, standard deviation; Sig. Statistical significance).

\begin{tabular}{|c|c|c|c|c|c|c|}
\hline $\begin{array}{l}\text { Vertical Installation } \\
\text { Location }(\mathrm{cm})\end{array}$ & $\begin{array}{c}\text { Arrow } \\
\text { Direction }\end{array}$ & $\begin{array}{c}\text { Average } \\
\text { DMTs (ms) }\end{array}$ & $\begin{array}{l}\text { SD } \\
(\mathrm{ms})\end{array}$ & $\begin{array}{l}\text { FRs } \\
(\%)\end{array}$ & $\mathbf{t}$ & Sig. \\
\hline \multirow{2}{*}{$y=270$} & $\mathrm{~L}$ & 1579.21 & 151.04 & 97.8 & \multirow{2}{*}{1.152} & \multirow{2}{*}{0.250} \\
\hline & $\mathrm{R}$ & 1592.64 & 393.26 & 98.94 & & \\
\hline \multirow{2}{*}{$y=240$} & $\mathrm{~L}$ & 1581.16 & 165.05 & 99.32 & \multirow{2}{*}{0.341} & \multirow{2}{*}{0.733} \\
\hline & $\mathrm{R}$ & 1578.77 & 192.79 & 99.32 & & \\
\hline \multirow{2}{*}{$y=210$} & $\mathrm{~L}$ & 1580.18 & 163.26 & 98.94 & \multirow{2}{*}{-1.042} & \multirow{2}{*}{0.297} \\
\hline & $\mathrm{R}$ & 1587.39 & 189.53 & 98.94 & & \\
\hline \multirow{2}{*}{$y=180$} & $\mathrm{~L}$ & 1580.56 & 197.17 & 99.32 & \multirow{2}{*}{1.136} & \multirow{2}{*}{0.256} \\
\hline & $\mathrm{R}$ & 1570.97 & 212.15 & 99.55 & & \\
\hline \multirow{2}{*}{$y=150$} & $\mathrm{~L}$ & 1583.28 & 174.64 & 99.02 & \multirow{2}{*}{2.134} & \multirow{2}{*}{0.033} \\
\hline & $\mathrm{R}$ & 1568.25 & 185.47 & 99.17 & & \\
\hline \multirow{2}{*}{$y=120$} & L & 1603.45 & 203.61 & 97.95 & \multirow{2}{*}{0.899} & \multirow{2}{*}{0.369} \\
\hline & $\mathrm{R}$ & 1595.97 & 219.29 & 97.65 & & \\
\hline \multirow{2}{*}{$y=90$} & L & 1634.96 & 243.34 & 99.24 & \multirow{2}{*}{2.926} & \multirow{2}{*}{0.003} \\
\hline & $\mathrm{R}$ & 1606.15 & 259.97 & 99.02 & & \\
\hline \multirow{2}{*}{$y=60$} & $\mathrm{~L}$ & 1625.2 & 189.67 & 98.26 & \multirow{2}{*}{1.235} & \multirow{2}{*}{0.217} \\
\hline & $\mathrm{R}$ & 1616.48 & 170.34 & 99.32 & & \\
\hline \multirow{2}{*}{$y=30$} & $\mathrm{~L}$ & 1767.01 & 302.66 & 99.02 & \multirow{2}{*}{9.1} & \multirow{2}{*}{0.000} \\
\hline & $\mathrm{R}$ & 1667.31 & 254.02 & 98.03 & & \\
\hline
\end{tabular}

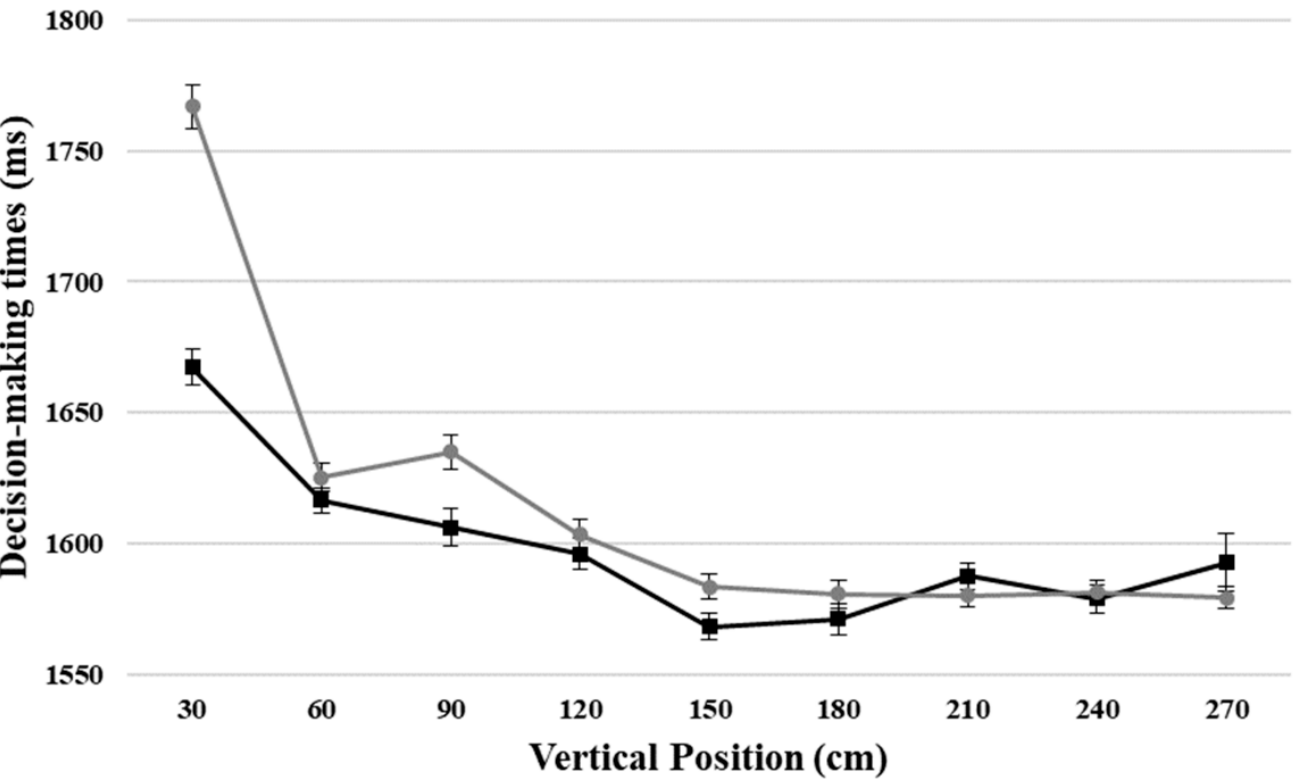

$\rightarrow$ Left Arrow $\rightarrow$ Right Arrow

Figure 8. Average DMTs according to the vertical installation location and arrow direction (the error bars represent standard errors).

\section{Discussion}

This study produced 198 virtual stimuli, and the DMTs of 120 participants were analyzed, according to the horizontal/vertical installation locations of the signs. The 
analysis revealed that (1) the average DMT and FRs according to the arrow direction of the signs, (2) the average DMT and FRs according to the horizontal installation location and arrow direction of the signs, and (3) the average DMT and FRs according to the vertical installation location and arrow direction of signs. These results inform the study's proposal regarding the optimal installation location of the signs.

First, the results confirmed that the right arrow of signs (average DMT $=1598.12 \mathrm{~ms}$, FRs $=98.88 \%$ ) exhibited shorter DMTs and higher FRs than the left arrow (average $\mathrm{DMT}=1614.98 \mathrm{~ms}$, FRs $=98.76 \%$ ).

This is likely because all participants were right-handed and right-side driving is performed in South Korea, where the experiment was conducted. According to a previous study, Scharine and McBeath [30] revealed that the learned driving patterns and genetic handedness correlate with the direction preferences of pedestrians, including right-handed and right-side driving subjects preferring to turn right, through an experiment performed in the T-maze. The same discovery was also observed in the results of a survey conducted by Veeraswamy et al. [28]. The choice between the left or right direction at a T-type intersection was affected by the handedness of participants and learned driving patterns. All participants in the experiment seemed to prefer the right direction as a result of their right-handed and right-side driving experience in South Korea. This may have resulted in shorter DMTs and higher FRs when the right direction was selected than when the left direction was selected according to the arrow direction at a T-type intersection.

Second, it was revealed that there were significant variances in DMTs, depending on the horizontal installation location of the signs (see Table 2), and depending on the arrow direction for each horizontal installation location (see Table 3 and Figure 7 ). There were significant variances in DMTs depending on the arrow direction at all horizontal installation locations except for $\mathrm{x}=0 \mathrm{~cm}(p=0.142>0.05)$, which was the central location of signs in the horizontal direction (see Table 3). At $x=-150 \mathrm{~cm}, x=-120 \mathrm{~cm}, x=-90 \mathrm{~cm}$, and $x=-60 \mathrm{~cm}$, which were located to the left of the center, the average DMTs were shorter and FRs was higher for the left arrow direction. At $x=60 \mathrm{~cm}, x=90 \mathrm{~cm}, x=120 \mathrm{~cm}$, and $x=150 \mathrm{~cm}$, which were located to the right of the center, the average DMTs were shorter and FRs was higher for the right arrow direction.

These results can be explained using the "Simon effect [31]" by the arrow direction and horizontal installation location of signs. The Simon effect occurs depending on the agreement between the arrow direction and horizontal installation location of the signs. The results of this study indicate that the Simon facilitation and interference effects occurred depending on the arrow direction and horizontal installation locations of the signs. Therefore, when the arrow direction of the signs is inconsistent with the horizontal installation location of the signs (e.g., when the arrow points to the right while the horizontal installation location is on the left side), the "Simon interference effect" occurs, FRs decrease, and DMTs increase. When the arrow direction of signs is consistent with the horizontal installation location of signs (e.g., when the arrow points to the left while the horizontal installation location is on the left side), the "Simon facilitation effect", FRs increase and DMTs decrease.

When the horizontal installation locations of signs were $x=-30 \mathrm{~cm}, x=0 \mathrm{~cm}$, and $x=30 \mathrm{~cm}$, however, the Simon effect, according to the arrow direction did not occur, and the average DMTs were found to be shorter for the right arrow direction. This was because all the participants were right-handed and right-side driving was performed in South Korea where the experiment was conducted [28,30]. This means that the Simon effect, according to the arrow direction of the signs occurs when the horizontal installation location of the signs is more than $60 \mathrm{~cm}$ away from the center. Hence, the results of this study indicate that the installation of signs on the same horizontal side as the arrow direction can contribute to reducing the DMTs of occupants in an evacuation situation due to the Simon facilitation effect.

Third, the experimental results revealed significant variances in DMTs depending on the horizontal installation location of the signs (see Table 4). There was, however, no 
significant variance in DMTs depending on the arrow direction for each vertical installation location of signs. As for the average DMTs for each vertical installation location, the highest average DMTs for both the left and right arrow directions were observed at $y=30 \mathrm{~cm}$. The lowest average DMTs were observed at $y=270 \mathrm{~cm}$ for the left arrow direction and at $y=150 \mathrm{~cm}$ for the right arrow direction. These results appear to be similar to the results of previous studies [26] in which the optimal installation location of the signs was proposed based on the analysis of the gaze point and eye movement data of the participants. In previous studies, the eye movement data obtained while the participants passed through the 2-m high maze-set were analyzed, and the gaze points of the evacuees were quantified in the horizontal and vertical directions according to the type of junction and corridor in which wayfinding decisions occurred. Vertical heights between 100 and $150 \mathrm{~cm}$ attracted the gaze of the largest number of people, and vertical heights between 0 and $50 \mathrm{~cm}$ attracted the gaze of the fewest number of people. Although a direct comparison cannot be performed, owing to the different heights of the walls used in the experiment ( $2 \mathrm{~m}$ for the previous studies [26] and $3 \mathrm{~m}$ for this study), the average DMTs seemed higher in this study when the participants observed the signs installed at low locations as with the results of the previous studies, because the participants were less likely to notice the low locations of the wall. Therefore, the experimental results of this study indicate that the installation of signs at the low locations of the wall is highly likely to adversely affect the DMTs of occupants in an evacuation situation.

Finally, DMTs according to the vertical and horizontal installation locations of the signs were compared to propose the installation location of the signs to support the fastest DMTs at a T-type indoor intersection. The above results showed that the DMTs of occupants are affected by the arrow direction and horizontal/vertical installation locations of the signs. In addition, in the case of the horizontal installation location, it was determined that the Simon effect occurs at locations more than $60 \mathrm{~cm}$ away from the center on both sides. In the case of the vertical installation location, it was determined that DMTs increase when the signs are installed at the low locations of the wall. In this study, the horizontal direction of the wall was divided into three areas based on the locations in which the Simon effect occurred $(\mathrm{x}=-150 \sim-60 \mathrm{~cm}, \mathrm{x}=-30 \sim 30 \mathrm{~cm}$, and $\mathrm{x}=60 \sim 150 \mathrm{~cm})$, and the vertical installation location was divided into three areas $(\mathrm{y}=30 \sim 90 \mathrm{~cm}, \mathrm{y}=120 \sim 180 \mathrm{~cm}$, and $y=210 \sim 270 \mathrm{~cm}$ ). The average ranks for each section were then compared to propose the optimal installation location of the signs (see Figure 9). In this instance, the average rank of each section represents the average of the ranks for each installation location presented in Figures 4-6.
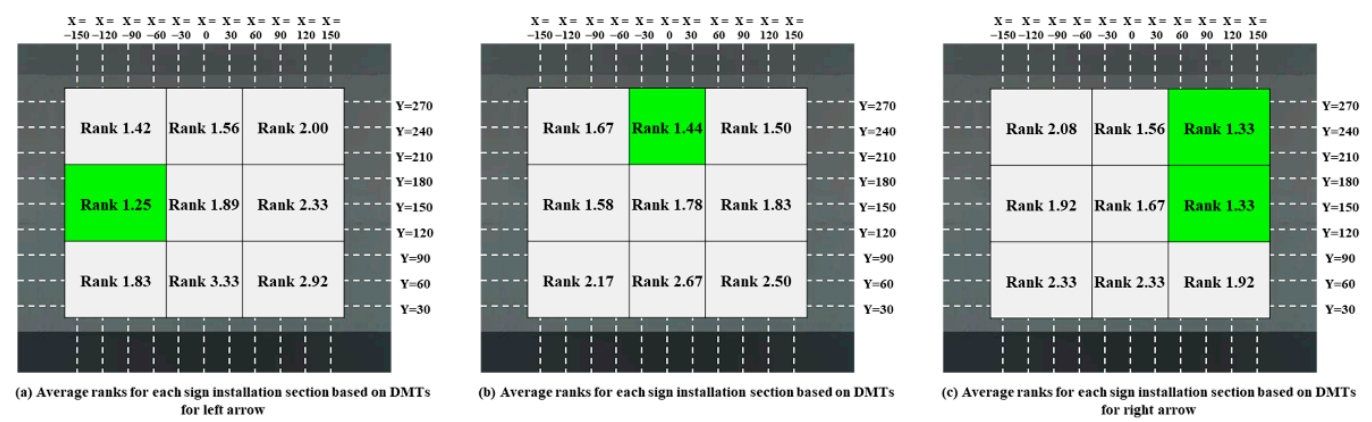

Figure 9. Average ranks for each sign installation section.

When the average ranks for each section were compared, the section exhibiting the lowest average rank (the lower average rank exhibits the faster DMTs) regardless of the arrow direction of signs was determined to be $\mathrm{x}=-30 \sim 30 \mathrm{~cm}$ and $\mathrm{y}=210 \sim 270 \mathrm{~cm}$ (Rank: 1.44), followed by $\mathrm{x}=60 \sim 150 \mathrm{~cm}$ and $\mathrm{y}=210 \sim 270 \mathrm{~cm}$ (Rank 1.50), and $\mathrm{x}=-150 \sim-60 \mathrm{~cm}$ and $y=120 \sim 180 \mathrm{~cm}$ (Rank 1.58). Hence, for the installation of signs regardless of the arrow direction, the highest efficiency can be obtained when it is installed at a height of more than $210 \mathrm{~cm}$ in the middle of the wall located in front of a T-type intersection. However, 
since this result does not consider the descent of the smoke layer, it needs to be corrected through an experiment considering the smoke layer.

For the left arrow direction of signs, the section that exhibited the lowest average rank was $\mathrm{x}=-150 \sim-60 \mathrm{~cm}$ and $\mathrm{y}=120 \sim 18 \mathrm{~cm}$ (Rank: 1.25), followed by $\mathrm{x}=-150 \sim-60 \mathrm{~cm}$ and $\mathrm{y}=210 \sim 270 \mathrm{~cm}$ (Rank: 1.42), and $\mathrm{x}=-60 \sim 60 \mathrm{~cm}$ and $\mathrm{y}=210 \sim 270 \mathrm{~cm}$ (Rank: 1.56). Hence, for the left arrow direction of signs, the highest efficiency can be obtained when it is installed at a height between 120 and $180 \mathrm{~cm}$ on the left side $(x=-150 \sim-60 \mathrm{~cm})$ of the wall located in front of a T-type intersection.

For the right arrow direction of signs, the sections that exhibited the lowest average rank were $\mathrm{y}=120 \sim 180 \mathrm{~cm}$ and $\mathrm{y}=210 \sim 270 \mathrm{~cm}$ for $\mathrm{x}=60 \sim 150 \mathrm{~cm}$ (Rank: 1.33 ). Hence, for the right arrow direction of signs, the highest efficiency can be obtained when it is installed at a height of more than $120 \mathrm{~cm}$ on the right side $(\mathrm{x}=60 \sim 150 \mathrm{~cm})$ of the wall.

\section{Conclusions}

This study used virtual stimuli to analyze the DMTs and FRs of participants according to the horizontal/vertical installation locations and arrow direction of signs at T-type indoor intersections. Based on the results, an optimal signs installation location was proposed.

First, the participants exhibited shorter DMTs and higher FRs for the right arrow direction of the signs. This indicates that the learned driving patterns and genetic handedness of the participants are correlated with the direction choice and DMTs.

Second, the Simon facilitation and interference effects occur depending on the arrow direction and horizontal installation location of the signs. In this instance, the Simon effect occurs when the horizontal installation location of the signs is more than $60 \mathrm{~cm}$ away from the center of the T-type indoor intersection on both sides.

Third, the DMTs of individuals increase when the vertical installation location of the signs is low.

Finally, in the case of a T-type indoor intersection, it is efficient to install the signs at a height of more than $120 \mathrm{~cm}$ on the same horizontal side as the arrow direction. Otherwise, the highest efficiency can be obtained when it is installed at a height of more than $210 \mathrm{~cm}$ in the middle of the wall.

This study is also valuable because it provides a scientific basis for selecting the installation location of signs, determined through an experimental analysis. The results of this study may be used to improve the installation guidelines and regulations for signs in the future. However, this paper has limitations as the participants were limited to university students and the experiment was performed on a virtual stimulus rather than an actual T-type intersection. Future studies should compare DMTs by age with participants from various age groups and compare DMTs in smoke conditions.

Author Contributions: Writing—original draft, Y.-H.B.; writing—review and editing, J.-Y.S., R.-S.O., H.-K.L., Y.-H.L., W.-H.H., and J.-H.C.; data curation, J.-Y.S. and Y.-H.L.; supervision, W.-H.H. and J.-H.C. All authors have read and agreed to the published version of the manuscript.

Funding: This research was funded by the National Research Foundation of Korea (NRF) grant (No. NRF-2018R1A2B3005951) and by the National Research Foundation of Korea (NRF) grant (No. NRF-2020R1A6A3A01099797) which was funded by the Korean government (Ministry of Education). This paper was funded by the "National Fire Agency" R\&D program (20016433).

Institutional Review Board Statement: The study was conducted according to the guidelines of the Declaration of Helsinki, and approved by the Institutional Review Board of Pukyong National University (protocol code 1041386-20180314-HR-005-03 and 14 March 2018.

Informed Consent Statement: Informed consent was obtained from all subjects involved in the study.

Data Availability Statement: Not applicable.

Acknowledgments: This paper was written by revising and developing the content of one chapter of the first author's PhD dissertation [32]. This work was supported by the National Research 
Foundation of Korea (NRF) grant (No. NRF-2018R1A2B3005951), which was funded by the Korean government (MSIT) and by the National Research Foundation of Korea (NRF) grant (No. NRF2020R1A6A3A01099797) which was funded by the Korean government (Ministry of Education). This paper was supported by the "National Fire Agency" R\&D program (20016433).

Conflicts of Interest: The authors declare no conflict of interest.

\section{References}

1. Kobes, M.; Helsloot, I.; de Vries, B.; Post, J.G. Building safety and human behaviour in fire: A literature review. Fire Saf. J. 2010, 45, 1-11. [CrossRef]

2. Modelling and Influencing Human Behaviour in Fire. Available online: https://onlinelibrary.wiley.com/doi/full/10.1002/fam. 2391 (accessed on 1 June 2021).

3. Agent-Based Simulation of Spatial Cognition and Way Finding in Building Fire Emergency Evacuation. Available online: https:/ / link.springer.com/chapter/10.1007/978-3-540-72108-6_17 (accessed on 1 June 2021).

4. $\quad$ NFSC (National Fire Safety Code) 303: Fire Safety Regulation of Exit Light and Exit Sign; Ministry of Public Administration and Security: Seoul, Korea, 2017.

5. National Fire Protection Association. Available online: https://www.nfpa.org/codes-and-standards/all-codes-and-standards/ list-of-codes-and-standards / detail?code $=101 \& y e a r=2018 /$ (accessed on 1 June 2021).

6. ISO 16069:2017. Graphical Symbols—Safety Signs—Safety Way Guidance Systems (SWGS); ISO: Geneva, Switzerland, 2017.

7. Xie, H.; Filippidis, L.; Galea, E.R.; Blackshields, D.; Lawrence, P.J. Experimental analysis of the effectiveness of emergency signage and its implementation in evacuation simulation. Fire Mater. 2012, 36, 367-382. [CrossRef]

8. Galea, E.R.; Xie, H.; Cooney, D.; Filippidis, L. Active dynamic signage system: A full-scale evacuation trial. In Proceedings of the 6th International Symposium on Human Behaviour in Fire 2015, Cambridge, UK, 28-30 September 2015; Interscience Communications Ltd.: London, UK, 2015; pp. 303-314.

9. Wong, L.T.; Lo, K.C. Experimental study on visibility of exit signs in buildings. Build. Environ. 2007, 42, 1836-1842. [CrossRef]

10. Jin, T.; Yamada, T.; Kawai, S.; Takahashi, S. Evaluation of the Conspicuousness Of Emergency Exit Signs. Fire Saf. Sci. 1991, 3, 835-841. [CrossRef]

11. Tuomisaari, M. Visibility of Exit Signs and Low-Location Lighting in Smoky Conditions; VTT, Technical Research Centre of Finland: Espoo, Finland, 1997.

12. $\mathrm{Ng}$, A.W.Y.; Chan, A.H.S. Effects of user factors and sign referent characteristics in participatory construction safety sign redesign. Saf. Sci. 2015, 74, 44-54. [CrossRef]

13. O'Neill, M.J. Evaluation of a Conceptual Model of Architectural Legibility. Environ. Behav. 1991, 23, 259-284. [CrossRef]

14. Kwee-Meier, S.T.; Mertens, A.; Schlick, C.M. Age-related differences in decision-making for digital escape route signage under strenuous emergency conditions of tilted passenger ships. Appl. Ergon. 2017, 59, 264-273. [CrossRef]

15. Kinateder, M.; Warren, W.H.; Schloss, K.B. What color are emergency exit signs? Egress behavior differs from verbal report. Appl. Ergon. 2019, 75, 155-160. [CrossRef]

16. Nilsson, D.; Frantzich, H.; Saunders, W. Influencing Exit Choice in the Event of a Fire Evacuation. Fire Saf. Sci. 2008, 9, 341-352. [CrossRef]

17. Olander, J.; Ronchi, E.; Lovreglio, R.; Nilsson, D. Dissuasive exit signage for building fire evacuation. Appl. Ergon. 2017, 59, 84-93. [CrossRef]

18. Mossberg, A.; Nilsson, D.; Andrée, K. Unannounced Evacuation Experiment in a High-Rise Hotel Building with Evacuation Elevators: A Study of Evacuation Behaviour Using Eye-Tracking. Fire Technol. 2020, 1-23. [CrossRef]

19. Proulx, G.Ë.; Kyle, B.; Creak, J. Effectiveness of a photoluminescent wayguidance system. Fire Technol. 2000, 36, 236-248. [CrossRef]

20. Ronchi, E.; Nilsson, D.; Kojić, S.; Eriksson, J.; Lovreglio, R.; Modig, H.; Walter, A.L. A Virtual Reality Experiment on Flashing Lights at Emergency Exit Portals for Road Tunnel Evacuation. Fire Technol. 2016, 52, 623-647. [CrossRef]

21. Fridolf, K.; Ronchi, E.; Nilsson, D.; Frantzich, H. Movement speed and exit choice in smoke-filled rail tunnels. Fire Saf. J. 2013, 59, 8-21. [CrossRef]

22. Collins, B.L.; Dahir, M.S.; Madrzykowski, D. Visibility of exit signs in clear and smoky conditions. Fire Technol. 1993, 29, 154-182. [CrossRef]

23. Church, R.; ReVelle, C. The maximal covering location problem. Pap. Reg. Sci. Assoc. 1974, 32, 101-118. [CrossRef]

24. Chen, C.; Li, Q.; Kaneko, S.; Chen, J.; Cui, X. Location optimization algorithm for emergency signs in public facilities and its application to a single-floor supermarket. Fire Saf. J. 2009, 44, 113-120. [CrossRef]

25. Zhang, Z.; Jia, L.; Qin, Y. Optimal number and location planning of evacuation signage in public space. Saf. Sci. 2017, 91, 132-147. [CrossRef]

26. Bae, Y.H.; Kim, Y.C.; Oh, R.S.; Son, J.Y.; Hong, W.H.; Choi, J.H. Gaze point in the evacuation drills: Analysis of eye movement at the indoor wayfinding. Sustainability 2020, 12, 2902. [CrossRef]

27. Kim, C.; Hur, M.; Oh, Y.; Choi, J.H.; Jeong, J.J. The Effect of the Running-Man Emergency Exit Sign and Its Installed Location on Human Directional Choice. Appl. Cogn. Psychol. 2016, 30, 1014-1019. [CrossRef] 
28. Wayfinding Behavior within Buildings-An International Survey. Available online: https://iafss.org/publications/fss/10/735 (accessed on 1 June 2021).

29. ISO 3864-3:2012. Graphical Symbols-Safety Colors; ISO: Geneva, Switzerland, 2012.

30. Scharine, A.A.; McBeath, M.K. Right-handers and Americans favor turning to the right. Hum. Factors 2002, 44, 248-256. [CrossRef] [PubMed]

31. Simon, J.; Wolf, J.D. Choice Reaction Time as a Function of Angular Stimulus-Response Correspondence and Age. Ergonomics 1963, 6, 99-105. [CrossRef]

32. Bae, Y.H. Design and Implementation of Evacuation Route Guidance System: Reflecting Human Behavior in Building Fire. Ph.D. Thesis, Kyungpook University, Daegu, Korea, 2020. 